\title{
Research on Passenger Flow Early Warning of Urban Rail Transit Station Based on System Dynamics
}

\author{
Hui Chen ${ }^{1}$, Bo Wang ${ }^{2}$, a , Wei He ${ }^{1}$ and Jianhu Zheng ${ }^{1}$ \\ ${ }^{1}$ Minjiang University, 350108Fuzhou, Fujian Province, China \\ 2 Beijing Transportation Information Center, 100044Beijing, China
}

\begin{abstract}
Large-scale passenger flows occur frequently during the peak hours of urban rail transit stations and on holidays. Thus, the timely and accurate early warning of impending large-scale passenger flows can positively impact the operational safety of the entire station. By further deepening the definition of passenger flow warnings in stations, a new model of urban rail transit station passenger flow based on system dynamics is constructed. The method of determining the key area of passenger flows in the early warning stage based on streamlines is proposed; the key indicators and thresholds affecting early warnings are studied. Finally, taking a typical station as an example, a station model is built using Anylogic software. The parameter sensitivity analysis is used to determine the impact of each key indicator on the passenger flow in the key area of the station early warning, and the reference threshold of each indicator is determined.
\end{abstract}

\section{Introduction}

Due to the special geographical locations and building structures of urban rail transit stations, passengers' personal safety and station operation safety can be compromised if very large passenger flows occur without warning. In such situations, station management personnel may be unable to issue warnings and take passenger flow control measures in time.

This important topic recently emerged in the research community and garnered significant attention. D. Li et al. [1] proposed the concept and framework of passenger flow early warning, and studied the level, rating basis, and indicator system of passenger flow early warning. L. Ding, B. Zhao et al. [2,3] studied early warning classification methods for passenger flow in the stations. $\mathrm{X}$. Xu et al. [4] studied the early warning methods of passenger flow risk in the business district from four aspects: regional density, section flow, bidirectional flow ratio, and average flow rate. Y. Zheng et al. [5] established a fuzzy synthetic evaluation model based on passenger flow density and evacuation time. $\mathrm{M}$. Li et al. [6] proposed a correlated early warning analysis process based on system dynamics (SD) equations. A pedestrian evacuation model considering residence time, crowd density, and exit distance was proposed by L. Fang et al. [7]. X. Ding et al. [8] promoted a passenger flow status identification method based on image and WiFi detection.

It should be noted that the early warning research on passenger flow in urban rail transit stations by domestic and international scholars is mostly focused on early warning levels, early warning indicators, safety assessments, etc. However, there are few studies investigating the thresholds of the early warning indicators. ${ }^{1}$ The early warning of passenger flow at stations is a complex system, which is closely related to the station layout, facility equipment capacity, organization of train operation, and passenger flow. Therefore, a novel station passenger flow model and simulation platform based on SD theory is proposed in this paper. Meanwhile, the station early warning methods and key indicator thresholds are studied to provide a rigorous foundation for the research.

\section{Definition of Passenger Flow Early Warning in Urban Rail Transit Stations}

According to the structure of urban rail transit stations, the actual operation of stations, the characteristics of passenger flows in the station, and the literature ${ }^{[1]}$, the passenger flow early warning of urban rail transit station is defined as follows. The station management personnel shall monitor the key indicators in key areas, and predict potential large passenger flows by comparing the indicator values to the indicator thresholds. Meanwhile, there should be sufficient time to take relevant measures to control the station passenger flow, and the safety of the station passengers is ensured during this period.

3 Early Warning Analysis of the Station Passenger Flow Based on an SD Model

\subsection{SD model construction for station passenger flow}


By analyzing the causal relationship between the three elements of the station facilities, passenger flow, and operational organization, a station passenger flow model based on SD theory is established. The system flow diagram is shown in Figure 1 and the relevant parameter variables in the model are shown in Table 1.

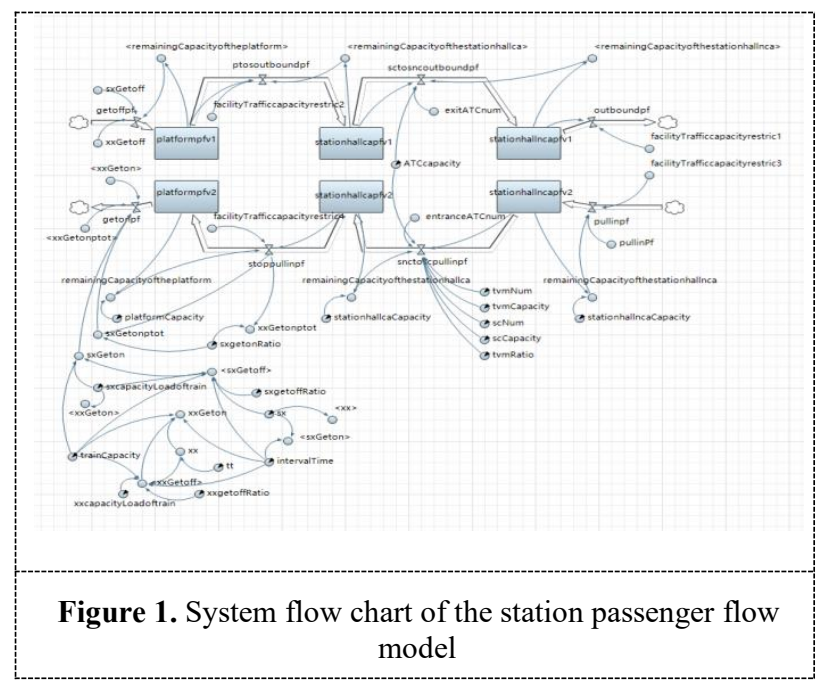

Table 1. Variable descriptions

\begin{tabular}{|c|c|}
\hline $\begin{array}{l}\text { Variabl } \\
\text { e/Para } \\
\text { meter } \\
\text { Code }\end{array}$ & $\begin{array}{l}\text { Variable/Para } \\
\text { meter Name }\end{array}$ \\
\hline $\mathrm{Q}_{1}$ & platformpfv 1 \\
\hline $\mathrm{Q}_{2}$ & Platformpfv2 \\
\hline $\mathrm{Q}_{3}$ & $\begin{array}{c}\text { Stationhallca } \\
\text { pfv1 }\end{array}$ \\
\hline $\mathrm{Q}_{4}$ & $\begin{array}{c}\text { Stationhallca } \\
\text { pfv2 }\end{array}$ \\
\hline $\mathrm{Q}_{5}$ & $\begin{array}{c}\text { Stationhallnc } \\
\text { apfv1 }\end{array}$ \\
\hline $\mathrm{Q}_{6}$ & $\begin{array}{l}\text { Stationhallnc } \\
\text { apfv2 }\end{array}$ \\
\hline $\mathrm{F}_{1 \text { in }}$ & getoffpf \\
\hline $\begin{array}{l}\mathrm{F}_{\text {1out }} \\
\mathrm{F}_{\text {3in }}\end{array}$ & $\begin{array}{c}\text { ptosoutbound } \\
\text { pf }\end{array}$ \\
\hline $\begin{array}{l}\mathrm{F}_{3 \text { out }} \\
\mid \mathrm{F}_{5 \text { in }}\end{array}$ & $\begin{array}{l}\text { sctosncoutbo } \\
\text { undpf }\end{array}$ \\
\hline $\mathrm{F}_{5 \text { out }}$ & outboundpf \\
\hline $\mathrm{F}_{6 \text { in }}$ & pullinpf \\
\hline
\end{tabular}

Variable/Parameter Definition

The real-time outbound

passenger flow at the platform.

The real-time inbound passenger flow at the platform.

The real-time outbound passenger flow in the paid area of the station hall.

The real-time inbound passenger flow in the paid area of the station hall. The real-time outbound passenger flow in the nonpaid area of the station hall.

The real-time inbound passenger flow in the nonpaid area of the station hall.

The real-time outbound passenger flow for getting off the trains.

The real-time outbound passenger flow from the platforms to the station hall.

The real-time outbound passenger flow from paid area

to the non-paid area in the station hall.

The real-time outbound passenger flow.

The real-time inbound passenger flow.
$\begin{array}{cc}\mathrm{F}_{6 \text { out }} & \text { snctoscpullin } \\ \mathrm{F}_{4 \text { in }} & \text { pf }\end{array}$

$\mathrm{F}_{4 \text { out }} \mid \mathrm{F}_{2 \mathrm{i}} \quad$ stoppullinpf

$F_{2 \text { out }}$ getonpf

$F_{\text {in }} \quad$ pullinPf

$\mathrm{RQ}_{1}$ remainingCap

$\mathrm{RQ}_{2}$ acityoftheplat form

remainingCap

$\mathrm{RQ}_{3}$ acityofthestati onhallca

remainingCap

$\mathrm{RQ}_{5}$ acityofthestati

RQ6 onhallnca

facilityTraffic

$\mathrm{RF}_{5 \text { out }}$ capacityrestri c1

$\mathrm{RF}_{6 \text { in }}$

facilityTraffic capacityrestri c3
$\mathrm{RF}_{1 \text { out } 3 \mathrm{i}}$
$\mathrm{n}$
facilityTraffic capacityrestri
c2

$\begin{array}{cc}\mathrm{RF}_{4 \text { out } 2 \mathrm{i}} & \text { facilityTraffic } \\ \mathrm{n} & \text { capacityrestri }\end{array}$ c4

$\mathrm{CQ}_{12}$

platformCapa city stationhallca Capacity stationhallnca

$\begin{array}{cc}\mathrm{CQ}_{56} & \text { Capacity } \\ \theta & \text { intervalTime }\end{array}$

$\mathrm{F}_{\text {S1in }} \quad$ sxGetoff

FXlin $_{\mathrm{Xx}} \quad \mathrm{xetoff}$

$\mathrm{SF}_{\text {2out }} \quad$ sxGeton

$\mathrm{XF}_{\text {2out }} \quad \mathrm{xxGeton}$
The real-time inbound passenger flow from the paid area to the non-paid area in the station hall.

The real-time inbound passenger flow from the station hall to the platforms.

The real-time inbound passenger flow for getting on the trains.

Number of inbound passengers.

The real-time remaining capacity of the platform.

The real-time remaining capacity of the paid area of the station hall.

The real-time remaining capacity of the non-paid area of the station hall.

The restricted capacity of the equipment at the connection of the non-paid area of the station hall and the outside of the stations in the outbound streamline.

The restricted capacity of the equipment at the connection of the non-paid area of the station hall and the outside of the station in the inbound streamline.

The restricted capacity of the equipment at the connection of the platform and the paid area of the station hall in the outbound streamline.

The restricted capacity of the equipment at the connection of the platforms and the paid area of the station hall in the inbound streamline.

The platform capacity.

The capacity of paid area in the station hall.

The capacity of the non-paid area in the station hall.

The departure interval time.

The passenger flow getting off the upward direction trains at arrival.

The passenger flow getting off the downward direction trains at arrival.

The available capacity for the upward direction trains at arrival.

The available capacity for the downward direction trains at arrival. 


\begin{tabular}{|c|c|c|}
\hline $\mathrm{SPF}_{2 \text { out }}$ & sxGetonptot & $\begin{array}{c}\text { The number of passengers for } \\
\text { the upward direction trains at } \\
\text { the platform. }\end{array}$ \\
\hline $\mathrm{XPF}_{2 \text { out }}$ & $\mathrm{xxGetonptot}$ & $\begin{array}{c}\text { The number of passengers for } \\
\text { the downward direction trains } \\
\text { at the platform. }\end{array}$ \\
\hline $\mathrm{N}_{1} / \mathrm{N}_{2}$ & $\begin{array}{l}\text { exitATCnum/ } \\
\text { entranceATC } \\
\text { num }\end{array}$ & $\begin{array}{l}\text { Number of exit/ entrance } \\
\text { ticket gates. }\end{array}$ \\
\hline $\mathrm{N}_{3} / \mathrm{N}_{4}$ & $\begin{array}{l}\text { tvmNum/ } \\
\text { scNum }\end{array}$ & $\begin{array}{l}\text { Number of ticket vending } \\
\text { machines (TVM) / number of } \\
\text { security checks. }\end{array}$ \\
\hline $\mathrm{C}_{\mathrm{N} 12}$ & ATCcapacity & The ticket gate capacity. \\
\hline $\begin{array}{l}\mathrm{C}_{\mathrm{N} 3} / \\
\mathrm{C}_{\mathrm{N} 4}\end{array}$ & $\begin{array}{l}\text { tvmCapacity/ } \\
\text { scCapacity }\end{array}$ & $\begin{array}{c}\text { The capacity of ticket vending } \\
\text { machines / the capacity of } \\
\text { security checks. }\end{array}$ \\
\hline$\rho_{\mathrm{N} 3}$ & tvmRatio & $\begin{array}{c}\text { The ratio of passengers who } \\
\text { need to purchase tickets at the } \\
\text { TVM in the inbound } \\
\text { passengers. } \\
\text { The ratio of alighting }\end{array}$ \\
\hline$\rho_{\text {sof }} / \rho_{\text {xof }}$ & $\begin{array}{l}\text { sxgetoffRatio } \\
\text { xxgetoffRatio }\end{array}$ & $\begin{array}{l}\text { The ratio of alighting } \\
\text { passengers of } \\
\text { upward/downward direction } \\
\text { trains. }\end{array}$ \\
\hline$\eta_{\mathrm{s}} / \eta_{\mathrm{x}}$ & $\begin{array}{l}\text { sxcapacityLo } \\
\text { adoftrain/xxc } \\
\text { apacityLoado } \\
\text { ftrain }\end{array}$ & $\begin{array}{c}\text { The load factors of } \\
\text { upward/downward direction } \\
\text { trains. }\end{array}$ \\
\hline$\rho_{\text {son }}$ & sxgetonRatio & $\begin{array}{l}\text { The proportion of passengers } \\
\text { who need to get on the } \\
\text { upward direction trains at the } \\
\text { station. }\end{array}$ \\
\hline $\mathrm{C}_{\text {train }}$ & trainCapacity & The train capacity. \\
\hline$\beta$ & $\mathrm{tt}$ & $\begin{array}{l}\text { The arrival time interval } \\
\text { between upward direction and } \\
\text { downward direction trains. }\end{array}$ \\
\hline
\end{tabular}

(1) The calculation equation of the state variable

$Q_{i}=\int\left[F_{\text {iin }}(t)-F_{\text {iout }}(t)\right] d t, i=1,2 \cdots \cdots 6$

(2) The calculation equations of the rate variables

- The passenger flow equations at the connected equipment are as follows:

$$
\begin{gathered}
F_{\text {iin }} \mid F_{\text {jout }}=\min \left\{R F_{\text {injout }}, R Q_{i},\left(\frac{Q_{j}}{\Delta t}\right)\right\}, i=3,1 ; j=1,4 \\
F_{5 \text { in }} \mid F_{3 \text { out }}=\min \left\{N_{1}, C_{N 12}, R Q_{5},\left(\frac{Q_{3}}{\Delta t}\right)\right\} \\
F_{4 \text { in }} \mid F_{6 \text { out }}=\min \left\{\begin{array}{l}
\min \left\{\left(\frac{Q_{6}}{\Delta t}\right) \cdot \rho_{N 3}, N_{3} \cdot C_{N 3}\right\} \\
\left(\frac{Q_{6}}{\Delta t}\right) \cdot\left(1-\rho_{N 3}\right), N_{4} \cdot C_{N 4}, N_{2} \cdot C_{N 12}, R Q_{4}
\end{array}\right\}
\end{gathered}
$$

- The passenger flow equations for the inbound and outbound flows in the stations are as follows:

$$
F_{\text {sout }}=\min \left\{\left(\frac{Q_{5}}{\Delta t}\right), R F_{\text {sout }}\right\}
$$

$$
F_{6 \text { in }}=\min \left\{R Q_{6}, R F_{6 \text { in }}, F_{\text {in }}\right\}
$$

- The passenger flow equations for the inbound and outbound flows in trains are as follows:

$$
\begin{gathered}
F_{1 \text { in }}=\min \left\{F_{S 1 \text { in }}+F_{X 1 \text { in }}, R Q_{1}\right\} \\
F_{\text {2out }}=\min \left\{S F_{\text {2out }}, S P F_{2 \text { out }}\right\}+\min \left\{X F_{\text {2out }}, X P F_{\text {2out }}\right\}
\end{gathered}
$$

(3) The calculation equations for the auxiliary variables

$$
R Q_{i}=R Q_{i+1}=C Q_{i(i+1)}-Q_{i}-Q_{i+1}, i=1,3,5
$$

\subsection{Determine streamline based judging criteria for key areas}

The streamlines of passenger flows in urban rail transit stations primarily consist of the outbound streamline and the inbound streamline. For the adjacent equipment passing these two streamlines, congestion can readily form if the passing capacity of the downstream equipment is smaller than that of the upstream equipment. Substantially, these streamlines are key areas for passenger flow early warning in the station. According to the characteristics of the SD model for station passenger flow, combined with the literature ${ }^{[1]}$, this paper only judges the station platform area, the paid area in the station hall, and the non-paid area in the station hall.

\subsection{Analysis of key elements and determination of key indicators' thresholds}

The analysis of the passenger flow composition, organization of train operation, carrying capacity of the key area, and capacity of passing equipment and facilities in each early warning area is carried out to determine the key factors affecting the area. In particular, the passenger flow density is the most direct factor to represent the risk of passenger flow ${ }^{[9]}$. The literature ${ }^{[1,3,7,8]}$ uses pedestrian density as an important monitoring indicator for station early warnings or safety assessments. Meanwhile, the station service level for pedestrians is also closely related to passenger flow density ${ }^{[10,11]}$. Therefore, the passenger flow density is used as a key indicator for monitoring the station's early warning area in this paper.

The early warning of the station passenger flow depends on the current regional passenger flows as well as the changing trends of passenger flows into/out of the area. It is necessary to comprehensively consider the relationship between the two to determine the key indicators' thresholds. The specific methods for the outbound streamline and the inbound streamline are as follows:

(1) Passenger flow early warning for the outbound streamline due to the lower passing capacity of downstream equipment compared to that of upstream equipment.

If one of the following three conditions is met:

$$
\begin{aligned}
& F_{S 1 \text { in }}+F_{X 1 \text { in }}>R F_{1 \text { out } 3 \text { in }} \cdot \theta \\
& R F_{1 \text { out } 3 \text { in }}>N_{1} \cdot C_{N 12} \\
& N_{1} \cdot C_{N 12}>R F_{\text {Sout }}
\end{aligned}
$$


Then, the thresholds of the key indicators must be determined by analyzing the following:

- Study the impact of different $\beta$ values on the real-time passenger flow of the corresponding early warning area and determine the thresholds of the key indicators.

- Study the impact of different $\theta$ values on $\mathrm{SF}_{2 \text { out, }}$ $\mathrm{XF}_{2 \text { out }}$, and the real-time passenger flow of the corresponding early warning area; determine the thresholds of the key indicators.

- Study the impact of different $F_{\text {Slin }}$ and Fxlin values on $\mathrm{SF}_{2 \text { out }}, \mathrm{XF}_{2 \text { out }}$, and the real-time passenger flow of the corresponding early warning area; determine the thresholds of the key indicators.

(2) Passenger flow early warning for the inbound streamline due to the lower passing capacity of downstream equipment compared to that of upstream equipment.

If one of the following three conditions is met:

$$
\begin{gathered}
S F_{2 \text { out }}+X F_{2 \text { out }}<R F_{4 \text { out } 2 \text { in }} \cdot \theta \\
R F_{4 \text { out } 2 \text { in }}<\min \left\{N_{3} \cdot C_{N 3}, N_{4} \cdot C_{N 4}, N_{2} \cdot C_{N 12}\right\} \\
\min \left\{N_{3} \cdot C_{N 3}, N_{4} \cdot C_{N 4}, N_{2} \cdot C_{N 12}\right\}<R F_{6 \text { in }}
\end{gathered}
$$

Then, the impact of different $\mathrm{F}_{6 \text { in }}$ values on the realtime passenger flow of the corresponding early warning area is studied and the thresholds of the key indicators are determined.

It can be seen from the above research that the determination of the threshold values of the station early warning indicators involves many factors, which are not fixed values. According to the characteristics of different stations, the early warning schemes of each station under different passenger flow conditions should be prepared well.

\section{Case Study}

A metro station in Fuzhou, China is selected as a prototype in this paper, and a station simulation model is constructed using Anylogic software. Subsequently, the early warning scheme of the station is studied. In this paper, the minimum unit time for system simulation is minutes, and the total simulation time is 180 minutes. The service level standards for each level of each passenger flow carrying area $[10,11]$ are shown in Table 2 . When the service level $F$ is reached, the passenger flow is blocked [10]. Therefore, the passenger flow carrying capacity of the studied area during the simulation process is defined as the passenger flow carrying capacity at the time when the service level $\mathrm{F}$ is reached. The platform area is $696 \mathrm{~m}^{2}$, the paid area in the station hall is $493 \mathrm{~m}^{2}$, and the non-paid area in the station hall is $635 \mathrm{~m}^{2}$. According to the layout and the capacity of the station facilities, the basic parameters of the model are set as shown in Table 3.

\begin{tabular}{|c|c|c|c|c|c|c|}
\hline $\begin{array}{l}\text { Service } \\
\text { Level }\end{array}$ & $\begin{array}{c}\text { Leve } \\
1 \mathrm{~A} \\
\left(\mathrm{~m}^{2} / \mathrm{p}\right. \\
\text { erson } \\
)\end{array}$ & $\begin{array}{c}\text { Leve } \\
1 \mathrm{~B} \\
\left(\mathrm{~m}^{2} / \mathrm{p}\right. \\
\text { erson } \\
)\end{array}$ & $\begin{array}{c}\text { Leve } \\
1 \mathrm{C} \\
\left(\mathrm{m}^{2} / \mathrm{p}\right. \\
\text { erson } \\
\quad) \\
\end{array}$ & $\begin{array}{c}\text { Leve } \\
1 \mathrm{D} \\
\left(\mathrm{m}^{2} / \mathrm{p}\right. \\
\text { erson } \\
)\end{array}$ & $\begin{array}{l}\text { Leve } \\
1 \mathrm{E} \\
\left(\mathrm{m}^{2} / \mathrm{p}\right. \\
\text { erson } \\
\quad) \\
\end{array}$ & $\begin{array}{c}\text { Leve } \\
1 \mathrm{~F} \\
\left(\mathrm{~m}^{2} / \mathrm{p}\right. \\
\text { erson } \\
)\end{array}$ \\
\hline $\begin{array}{c}\text { Platfor } \\
\text { m } \\
\text { Paid }\end{array}$ & $>1.2$ & $\begin{array}{l}(0.9, \\
1.2]\end{array}$ & $\begin{array}{l}0.6, \\
0.9]\end{array}$ & $\begin{array}{c}(0.3, \\
0.6]\end{array}$ & $\begin{array}{l}(0.2, \\
0.3]\end{array}$ & $\leq 0.2$ \\
\hline $\begin{array}{l}\text { Area in } \\
\text { the } \\
\text { station }\end{array}$ & $>3.3$ & $\begin{array}{l}(2.3, \\
3.3]\end{array}$ & $\begin{array}{l}(1.4, \\
2.3]\end{array}$ & $\begin{array}{c}(0.9, \\
1.4]\end{array}$ & $\begin{array}{l}(0.5, \\
0.9]\end{array}$ & $\leq 0.5$ \\
\hline $\begin{array}{l}\text { Non- } \\
\text { paid } \\
\text { area in } \\
\text { the } \\
\text { station }\end{array}$ & $>3.3$ & $\begin{array}{l}(2.3, \\
3.3]\end{array}$ & $\begin{array}{l}(1.4, \\
2.3]\end{array}$ & $\begin{array}{l}(0.9, \\
1.4]\end{array}$ & $\begin{array}{l}(0.5 \text {, } \\
0.9]\end{array}$ & $\leq 0.5$ \\
\hline
\end{tabular}

Table 2 Service Level Standards for Each Passenger Flow Carrying Area

\begin{tabular}{|c|c|c|c|c|}
\hline $\begin{array}{c}\mathrm{CQ}_{12} / \text { Perso } \\
\mathrm{n}\end{array}$ & $\begin{array}{l}\mathrm{CQ}_{34} / \\
\text { Person }\end{array}$ & $\begin{array}{c}\mathrm{CQ}_{56} / \\
\text { Perso } \\
\mathrm{n} \\
\end{array}$ & $\begin{array}{c}\mathrm{C}_{\mathrm{N} 4} /(\text { Pers } \\
\text { on / } \\
\text { minute }) \\
\end{array}$ & $\begin{array}{c}\mathrm{C}_{\mathrm{N} 3} /(\text { Pers } \\
\text { on / } \\
\text { minute }) \\
\end{array}$ \\
\hline 3480 & 986 & 1270 & 20 & 1.3 \\
\hline $\begin{array}{c}\mathrm{N}_{1} / \text { per } \\
\text { machine }\end{array}$ & $\begin{array}{c}\mathrm{N}_{2} / \text { per } \\
\text { machin } \\
\mathrm{e}\end{array}$ & $\begin{array}{c}\mathrm{N}_{3} / \text { per } \\
\text { machi } \\
\text { ne }\end{array}$ & $\begin{array}{c}\mathrm{N}_{4} / \text { per } \\
\text { machine }\end{array}$ & $\begin{array}{c}\mathrm{C}_{\text {train }} / \\
\text { Person }\end{array}$ \\
\hline 12 & 8 & 12 & 3 & 1460 \\
\hline $\begin{array}{c}\mathrm{RF}_{6 \text { in }} /(\text { Pers } \\
\text { on / } \\
\text { minute })\end{array}$ & $\begin{array}{c}\mathrm{RF}_{5 \text { out }} /( \\
\text { Person } \\
/ \\
\text { minute } \\
\text { ) }\end{array}$ & $\begin{array}{c}\mathrm{RF}_{\text {lout3 }} \\
\text { in } /(\mathrm{Per} \\
\text { son / } \\
\text { minut } \\
\text { e) }\end{array}$ & $\begin{array}{c}\mathrm{RF}_{4 \text { out } 2 \text { in }} \\
/(\text { Person / } \\
\text { minute })\end{array}$ & $\begin{array}{c}\mathrm{C}_{\mathrm{N} 12} /(\text { Pers } \\
\text { on / } \\
\text { minute })\end{array}$ \\
\hline 572 & 858 & 234 & 156 & 30 \\
\hline
\end{tabular}

Table 3 Basic Parameter Settings of the Station Model

\subsection{Criteria for determining the key area of the station early warning}

According to the method described in Section 3.2, the equipment capacities of the outbound and inbound streamlines of the station are determined separately:

(1) The outbound streamline: Since $R F_{\text {5out }}>C_{N 12} \cdot N_{1}>R F_{\text {lout3in }}$, it is easy to form congestion at the platform if and only if $F_{\text {Slin }}+F_{X 1 \text { lin }}>R F_{\text {lout3in }} \cdot \theta$

(2) The inbound streamline: Since $\min \left\{N_{3} \cdot C_{N 3}, N_{4} \cdot C_{N 4}, N_{2} \cdot C_{N 12}\right\}<R F_{6 i n}$, it is easy to form congestion at the non-paid area in the station hall. In addition, it is easy to form congestion at the platform when $S F_{2 \text { out }}+X F_{2 \text { out }}<R F_{4 \text { out } 2 \text { in }} \cdot \theta$.

Therefore, it can be determined that the platform area and the non-paid area of the station hall are the early warning key areas in the station.

\subsection{Threshold study for the key indicators in the station early warning}

According to the method described in Section 3.3, the key indicators and their threshold values of the early warning at the platform and the non-paid area in the station hall are studied. 


\subsubsection{Threshold analysis of key early warning indicators in the platform area.}

(1) The influence of the arrival time interval between the upward direction and the downward direction trains $(\beta$ value) on the real-time passenger flow of the platform and alighting passenger flow.

According to the traffic statistics and passenger flow statistics of the passenger flow peak hours of Fuzhou Metro Line 1, the model parameters are set to the average values. The details are shown in Table 4 . In the model, $\beta$ $\in[0,3]$, and the parameter sensitivity analysis is performed with a one unit step size. The relationship between the $\beta$ value and the real-time passenger flow of the non-paid area in the station hall is shown in Figure 2. The relationship between the $\beta$ value and the real-time alighting passenger flow is shown in Figure 3. The relationship between the $\beta$ value and the real-time passenger flow at the platform is shown in Figure 4.

Table 4 Basic parameters of train operations and passenger flow

\begin{tabular}{cccccccc}
\hline$\rho_{\mathrm{N} 3}$ & $\begin{array}{c}\theta / \\
\text { minu } \\
\text { te }\end{array}$ & $\rho_{\text {son }}$ & $\eta_{\mathrm{x}}$ & $\rho_{\text {sof }}$ & $\eta_{\mathrm{s}}$ & $\rho_{\mathrm{xof}}$ & $\mathrm{C}_{\text {train }}$ \\
\hline 0.3 & 4 & 0.6 & 0.9 & 0.5 & 0.8 & 0.4 & 1460 \\
\hline
\end{tabular}

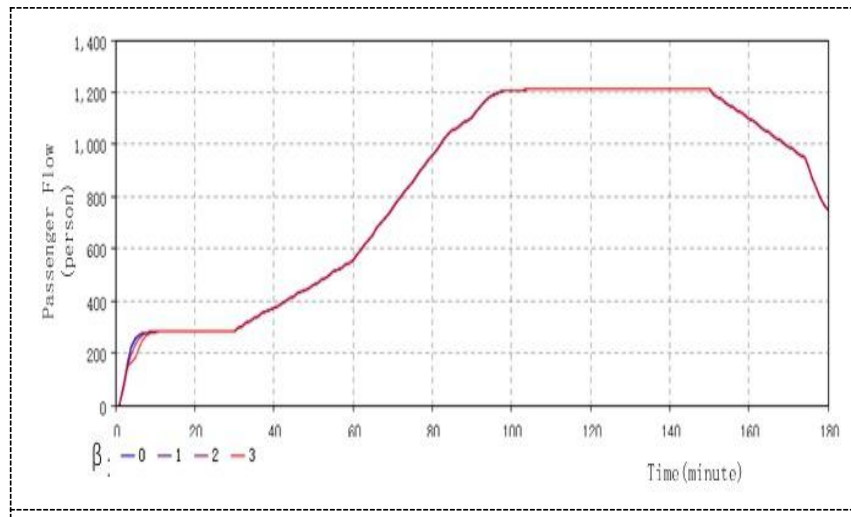

Figure 2. The relationship between the $\beta$ value and the realtime passenger flow of the non-paid area in the station hall

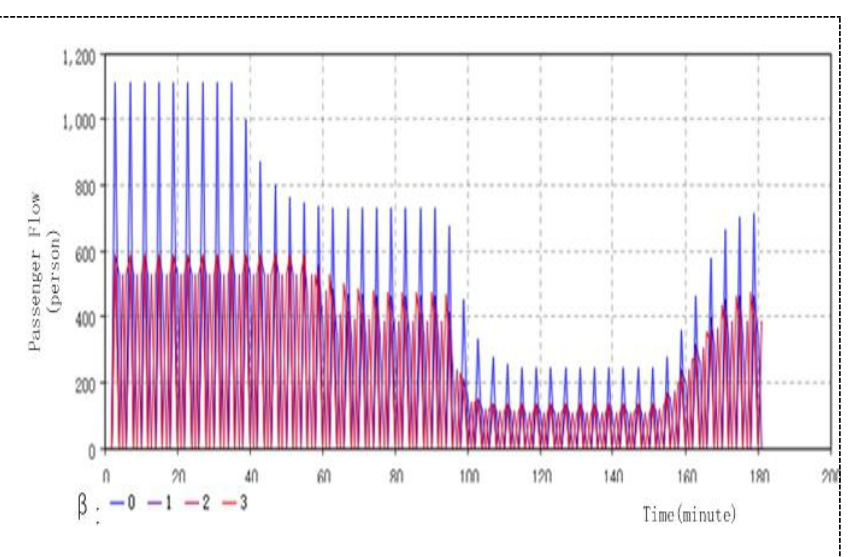

Figure 3. The relationship between the $\beta$ value and the realtime alighting passenger flow

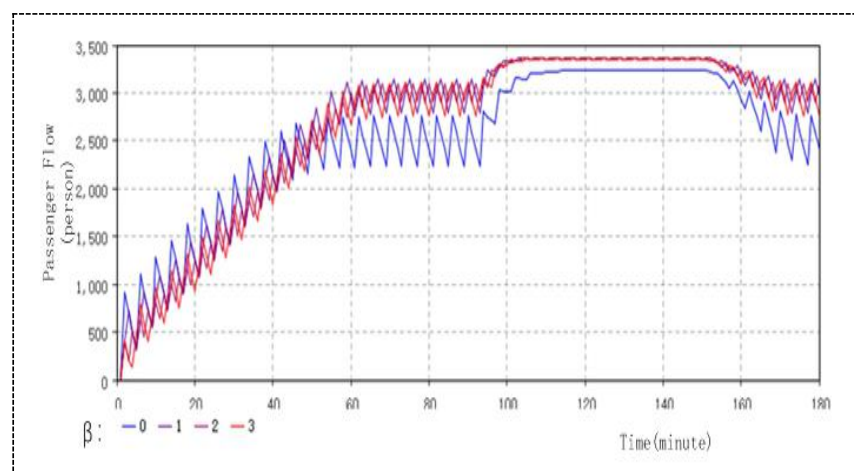

Figure 4. The relationship between the $\beta$ value and the realtime passenger flow at the platform

It can be seen from Figure 2 that the $\beta$ value does not affect the passenger flow of the non-paid area in the station hall. Since the inbound passenger flow is too large in the station, the passenger flow in the non-paid area of the station becomes close to its designed capacity at 98 minutes, causing the passenger flow in the station to block.The platform area also approaches the designed capacity in nearly 98 minutes, as shown in Figure 4. Therefore, when analyzing the influence of different $\beta$ values on the real-time passenger flow at the platform, the influence of the passenger flow blockage caused by the passenger flow in the non-paid area of the station should be excluded.

It can be seen from Figures 3 and 4 that when $\beta=0$, this parameter can significantly affect the real-time passenger flow at the platform and the alighting passenger flow. Meanwhile, the station area is at the service level D level and above for 165 minutes. From the 39th minute onwards, due to the limitation at the platform capacity, the passengers getting off the train are blocked; some could not even get off the train. This state continues until the end of the simulation. For $\beta=1,2$, and 3 , the situation is alleviated. Therefore, $\beta=0$ is assumed in the following study of thresholds of early warning indicators.

(2) Influence of the departure interval time $(\theta)$ on alighting passenger flow and passenger flow at the platform.

According to a statistical investigation on the departure interval time of China's subway lines, most of the results are in the range of 2-5 minutes. Therefore, $\theta \in[2,5]$, where the parameter sensitivity analysis is performed with a step size of one.

- Influence of departure interval time $(\theta)$ on alighting passenger flow

With the station model parameters, the alighting passenger flow at a departure interval $\theta$ is calculated to be 1110 persons. If the remaining capacity at the platform is less than the number of alighting passengers, then the congestion prevents some passengers from getting off the train. It can be estimated that alighting passenger flow is affected when the service level at the platform is E or higher. The relationship between $\theta$ and the real-time passenger flow at the platform is shown in Figure 5. 


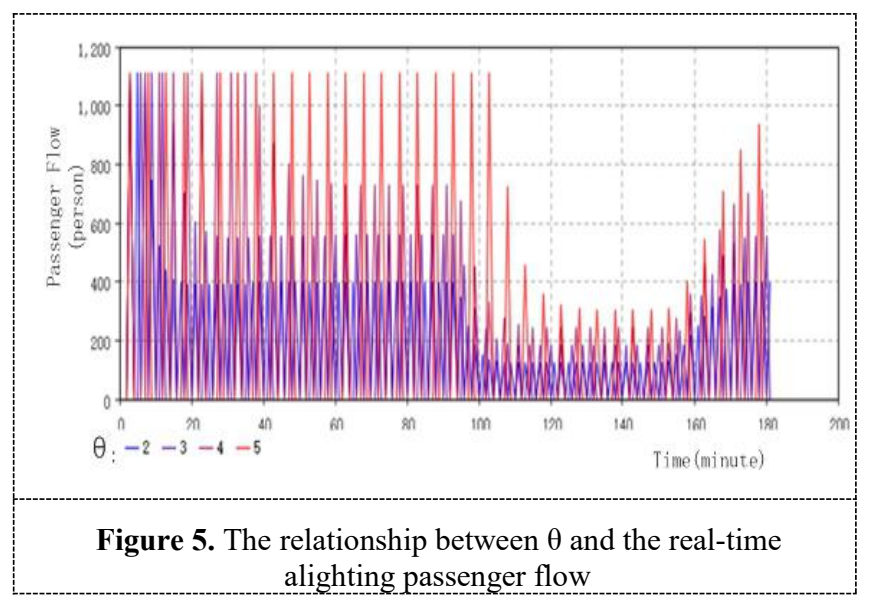

- Influence of the departure interval time $(\theta)$ on passenger flow at the platform

The relationship between $\theta$ and the real-time passenger flow at the platform is shown in Figure 6.

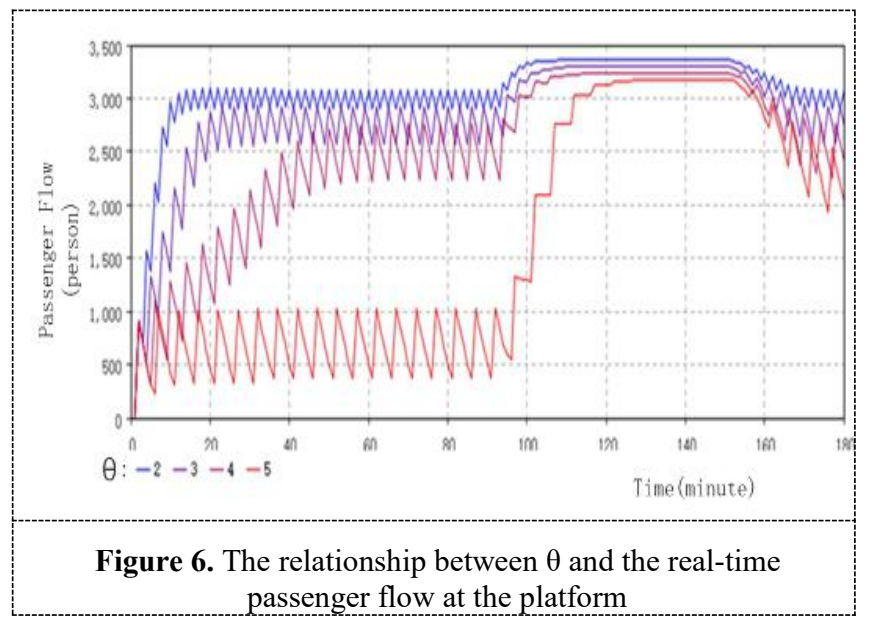

According to the statistics of the simulation data, the influence of $\theta$ on the service level of the platform is shown in Table 5. This table summarizes the average scale of the passenger flow during the peak hours of the station. When $\theta=5$, the triggering times of both the $D$ level and the E-level are similar to when the passenger flow rates of the non-paid area in the station hall is at or above the capacity limit. Excluding this factor, it can be considered that the service level of the station passenger flow is maintained at or below the D-level at the departure interval time.

Table 5 Correspondence between $\theta$ and triggering time / duration time of each station service level

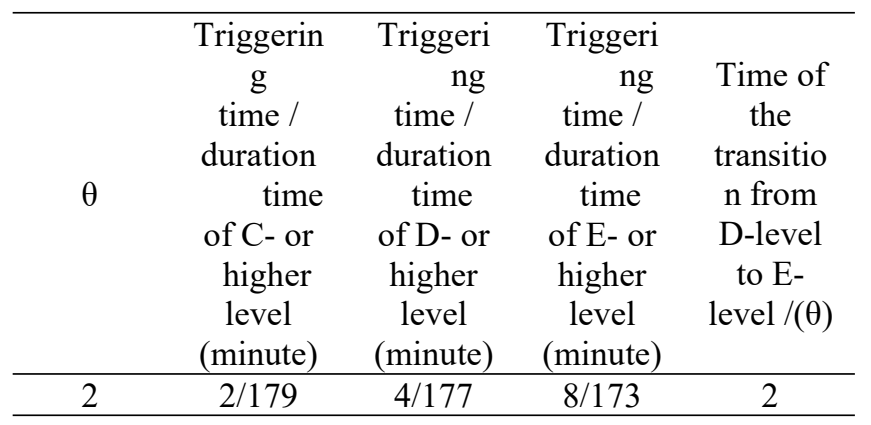

\begin{tabular}{ccccc}
\hline 3 & $2 / 177$ & $5 / 174$ & $14 / 166$ & 3 \\
4 & $2 / 17$ & $10 / 165$ & $34 / 125$ & 6 \\
5 & $2 / 120$ & $97 / 84$ & $107 / 67$ & $/$ \\
\hline
\end{tabular}

It can be seen from the above analysis that at a fixed passenger flow rate of boarding and alighting, the shorter the departure interval times result in shorter transition times at the platform service level. Considering that the station staff needs time to take necessary measures to control the passenger flow after receiving an alarm, it is recommended that when $\theta \leq 3$, the warning threshold of the station platform should be taken as the C-level. When $\theta=4$, the warning threshold can take the D-level. When $\theta$ $\geq 5$, the warning threshold can take the E-level.

- The influence of different alighting passenger flow values $F_{S l i n}$ and $F_{X l i n}$ on the real-time passenger flow at the platform

In this paper, through a comparative experiment of two setting parameters $\rho_{\text {sof }}$ and $\rho_{x o f}$, we study the influence of different passenger flow scales on the realtime passenger flow at the platform. We choose the departure interval $\theta=3$ minutes, which is common in the peak hours for the subways in major Chinese cities. The specific parameter settings and the corresponding passenger flow scale in a departure interval time are shown in Table 6. The effect of different passenger flow scales on the real-time passenger flow at the platform is shown in Figure 7.

Table 6 The relationship between different $\rho_{\text {sof }}$ and $\rho_{\text {xof }}$ values and the alighting passenger flow scales

\begin{tabular}{ccccc}
\hline$\rho_{\text {xof }}$ & 0.8 & 0.7 & 0.6 & 0.5 \\
$\rho_{\text {sof }}$ & 0.9 & 0.8 & 0.7 & 0.6 \\
$\mathrm{~F}_{\mathrm{S} 1 \text { in }}+\mathrm{F}_{\mathrm{X} 1 \text { in }}($ person/departur & 210 & 185 & 160 & 135 \\
$\mathrm{e}$ interval time) & 6 & 7 & 8 & 9 \\
$\rho_{\text {xof }}$ & 0.4 & 0.3 & 0.2 & 0.1 \\
$\rho_{\text {sof }}$ & 0.5 & 0.4 & 0.3 & 0.2 \\
$\mathrm{~F}_{\mathrm{S} 1 \text { in }}+\mathrm{F}_{\mathrm{X} 1 \text { in }}$ (person/departur & 1110 & 861 & 612 & 365 \\
$\mathrm{e}$ interval time) & & & \\
\hline
\end{tabular}

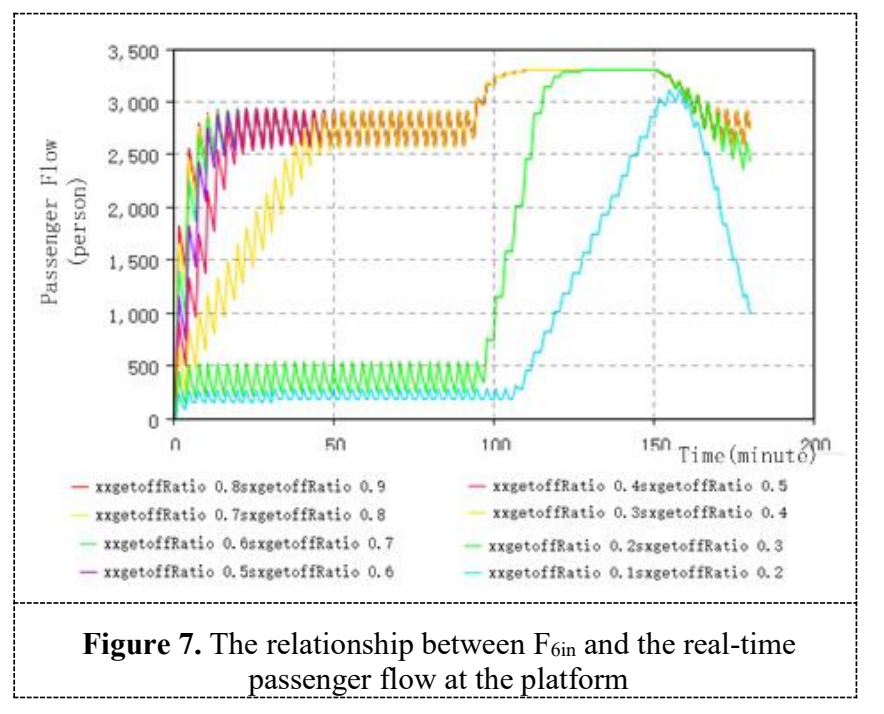

It can be seen from the simulation data that sxgetoffRatio $=0.4 /$ xxgetoffRatio $=0.3$ is the demarcation 
point. More specifically, when the number of alighting passengers is greater than 861 in a departure interval time, the influence of each passenger flow scale on the passenger flow at the platform is not significant. The transition from the D-level to the E-level occurs in the 2-3 departure interval time. When the number of alighting passengers is less than 861 , the impact on the passenger flow at the platform is little and does not cause the passengers to be detained in the station. In this case, we exclude the factor that the passenger flow is blocked in the station when the passenger flow in the non-paid area reaches its capacity limit.

\subsubsection{Threshold analysis of key early warning indicators in the non-paid area of the station hall}

Based on the method described in Section 3.2, we study the influence of different inbound passenger flow $F_{6 i n}$ values on the passenger flow of the corresponding early warning area. In this study, $\mathrm{F}_{6 \text { in }} \in[20,90]$, the parameter sensitivity analysis is carried with a step size of 10 . The influence of the $\mathrm{F}_{6 \text { in }}$ value on the real-time passenger flow of the non-paid area of the station hall is shown in Figure 8.

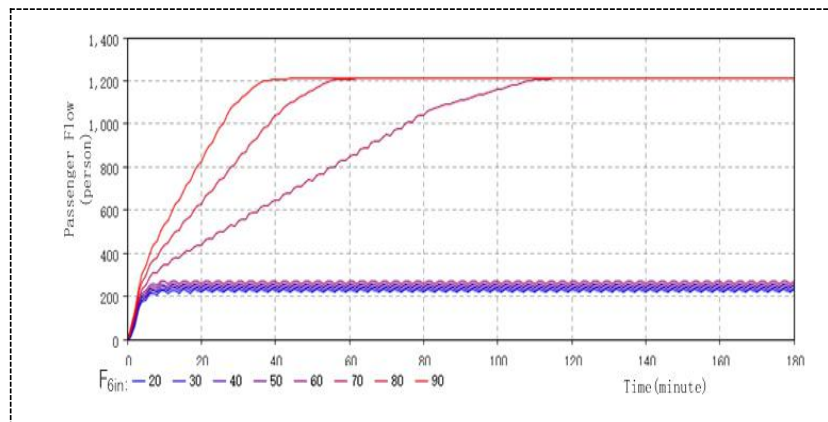

Figure 8. The relationship between different $\mathrm{F}_{6 \text { in }}$ values and the real-time passenger flow of the non-paid area in the station hall

It can be seen from the simulation data that $\mathrm{F}_{6 \mathrm{in}}=70$ person $/ \mathrm{min}$ is the dividing line. When $\mathrm{F}_{6 \text { in }}<70$ person $/ \mathrm{min}$, there is no congestion in the non-paid area of the station hall. Therefore, when $\mathrm{F}_{6 \text { in }} \geq 70$ person/min, the warning time should be determined according to the real-time situation of the passenger flow in the non-paid area of the station hall.

\section{Conclusion}

1) According to the real experience of station operations, we have further enhanced the definition of the station early warning and established the station passenger flow model based on system dynamics.

2) We have proposed a specific method for determining the key areas of the station early warning based on streamlines as well as the threshold values of key indicators.

3) Taking a subway station in a certain city of China as an example, we have verified the feasibility of the station model in a simulation study using Anylogic software.

4 ) This paper only focuses on ordinary stations in subway lines, and further research is needed for transfer stations.

\section{Acknowledgments}

This work is supported by Beijing Natural Science Foundation Key Project(8171003); Fuzhou Science and Technology Plan Project(2018-G-93).

\section{References}

[1] D.W. Li, Y.X. Sun , J.L. Huang, Ur. Rap. Rail. Tran.26(2)62-66(2013) DOI=10.3969/j.issn.16726073.2013 .02 .016 .

[2] L. Ding, Study on passenger flow early warning and coping method of urban rail transit transfer station .Nanjing. Univ. Sci. Technol. 72(2012)

[3] B.F. Zhao, X.L. Zou, X.Y. Qu,.Ur. Mas. Tran. 9 107-115(2017)

$\mathrm{DOI}=10.16037 / \mathrm{j} .1007-$ 869x.2017.09.022.

[4] X. Xu, M Y N L, Proc - 2010 IEEE Int. Conf. Emerg. Manag. Manag. Sci. 310-313(2010).

[5] Y.X. Zheng, Y. Qin, J.Y. Guo, L.M. Jia , J.H. Gao, 3rd Int. Conf. Electr. Inf. Technol. Rail. Transp. EITRT 2017 - Transp. 10 725-734(2017)

[6] M. Li, Y.H. Wang, J.L. Wu, L.M. Jia, China Saf. Sci. J. $24 \quad 22-26(2014)$.DOI= 10.16265/j.cnki.issn1003-3033.2014.04.012

[7] F.Li, S.Chen, X.Wang, F.Feng, Proced - Soc. Behav. Sci. 138 314-322(2014).DOI= 10.1016/j.sbspro.2014.07.209

[8] X.Ding, Z.Liu , H.Xu, J. Vis. Commun. Image. Represent. $\quad 58 \quad 119-129(2019)$.DOI= 10.1016/j.jvcir.2018.11.033

[9] T. Li, L.Z. Jin, Y.N. Ma , W.J. Zhu, Saf. Sci. Technol. 8 75-80 (2012).

[10] J.J. FRUIN, Pedestrian Planning and Design (New York: Metropolitan Association of Urban Designers and Environmental Planners, 1971)

[11] D.W. Li, B.M. Han ,Pedestrian Traffic (Bei jing: China Communications Press, 2011). 403- 405. 